\title{
PENANGKAPAN IKAN DEMERSAL DENGAN PANCING RAWAI DASAR DI PERAIRAN KABUPATEN BARRU, SULAWESI SELATAN
}

\author{
Enjah Rahmat \\ Teknisi Litkayasa pada Balai Riset Perikanan Laut, Muara Baru-Jakarta
}

Teregristasi I tanggal: 5 Mei 2006; Diterima setelah perbaikan tanggal: 11 Desember 2006; Disetujui terbit tanggal: 5 Maret 2007

\section{PENDAHULUAN}

Secara administratif, Kabupaten Barru termasuk ke dalam wilayah Propinsi Sulawesi Selatan dan berada di pesisir Selat Makassar yang berjarak \pm 100 $\mathrm{Km}$ ke arah utara dari Kota Makassar. Kabupaten Barru terdiri atas 5 Kecamatan, yaitu Tanete Rilau, Barru, Balusu, Suppeng Riaja, dan Mallusetasi.

Sumber daya perikanan demersal di Selat Makassar merupakan sasaran penangkapan masyarakat nelayan di sepanjang pantai Selat Makassar. Untuk menangkap berbagai jenis ikan demersal ini, nelayan di Kabupaten Barru pada umumnya menggunakan alat tangkap pancing rawai dasar. Hasil tangkapan utama ikan demersal di daerah ini adalah ikan kakap merah (Lutjanidae) dan ikan kerapu (Serranidae). Berdasarkan pada data laporan Dinas Perikanan dan Kelautan Kabupaten Barru pada tahun 2003, hasil tangkapan demersal yang utama adalah ikan kakap dan kerapu. Volume penangkapan ikan kakap dan kerapu masing-masing berturut-turut 49,3 dan 83,3 ton dengan jumlah armada 39 kapal rawai dasar.

Pancing rawai dasar adalah tipe rawai yang dipakai untuk menangkap ikan-ikan yang hidup di dasar perairan. Bentuk pancing ini agak berbeda dengan rawai tuna karena fungsi memang untuk menangkap ikan-ikan dasar (Subani et al., 1989).

\section{BAHAN DAN METODE}

\section{a. Kapal Penangkapan}

Kapal yang digunakan kapal atau perahu jukung (katinting), bahan utama kayu dengan panjang 7 sampai dengan $9,5 \mathrm{~m}$, lebar 50 sampai dengan 65 $\mathrm{cm}$, dan dalam 60 sampai dengan $70 \mathrm{~cm}$. Mesin penggerak merk Honda 13 PK atau Mitsubishi 16,5 PK. Perahu katinting ini diawaki oleh 2 sampai dengan 3 orang tapi pada umumnya diawaki oleh 2 orang anak buah kapal.

\section{b. Bahan dan Konstruksi Alat Tangkap}

Alat tangkap pancing rawai dasar terdiri atas komponen-komponen utama yaitu tali utama, tali cabang, mata pancing, pelampung, dan pemberat (Gambar 1). Tali utama dan tali cabang yang digunakan terbuat dari bahan nylon monofilamen. Jenis mata pancing adalah mata pancing yang berkait balik, mata pancing ini menggunakan ikan umpan segar dan pemberat yang digunakan terbuat dari batu, besi, atau jangkar.

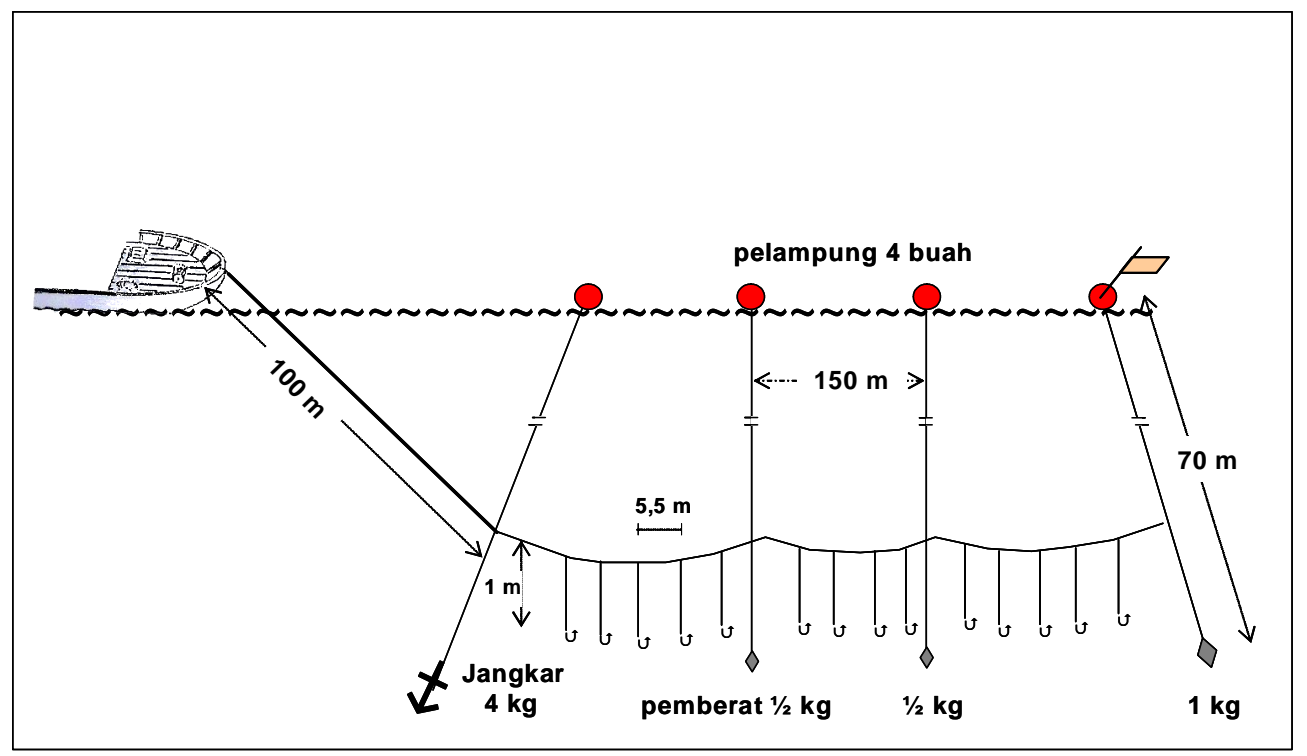

Gambar 1. Konstruksi alat tangkap pancing rawai dasar nelayan Kabupaten Barru. 
Jumlah mata pancing 430 buah dengan jarak antar mata pancing sejauh $5,5 \mathrm{~m}$. Tali utama berupa tali nylon monofilamen No.1.500 dan tali cabang adalah tali nylon monofilamen No.500. Mata pancing yang digunakan jenis mata pancing berkait balik pada umumnya No.6 atau 8.

Pancing rawai dasar menggunakan 2 buah pemberat yang terbuat dari bahan batu dengan bobot $1 / 2 \mathrm{~kg}$ dan 1 buah pemberat $1 \mathrm{~kg}$ serta 1 buah jangkar $4 \mathrm{~kg}$. Pelampung yang digunakan 4 buah dipasang pada ujung tali utama, bagian tengah tali utama, dan dipangkal tali utama.

Tujuan pemasangan pemberat dan pelampung ini adalah untuk menjaga agar pancing rawai dapat terentang dengan sempurna sehingga dapat menghasilkan dengan baik. Pelampung juga berfungsi sebagai tanda pengoperasian alat tangkap ini dan untuk memudahkan dalam memonitor posisi dari alat tangkap tersebut.

\section{c. Cara Pengoperasian}

Teknik pengoperasian alat tangkap pancing rawai dasar sebagai berikut:

1. Mata pancing diberi umpan terlebih dahulu, kegiatan ini dilakukan dalam perjalanan menuju daerah penangkapan. Jenis-jenis ikan umpan segar yang digunakan adalah japuh, cumi, layang, dan lain-lain.

2. Penentuan lokasi (daerah penangkapan) dengan cara mengukur kedalaman dan memeriksa jenis atau tipe dasar perairan. Alat bantu yang digunakan untuk penentuan lokasi ini adalah tali yang telah ditandai untuk setiap $5 \mathrm{~m}$ dengan suatu ikatan pada tali tersebut. Pada bagian ujung tali diberi pemberat (batu). Kemudian pemberat dan tali tersebut dijatuhkan sampai dengan mencapai dasar perairan sehingga kedalaman dapat diketahui dan dari pantulan pemberat di dasar perairan para nelayan dapat mengetahui tipe dasar perairan, berlumpur, atau berkarang.

3. Pemberat dan pelampung pertama yang terhubung dengan ujung tali utama diturunkan terlebih dahulu.

4. Pancing rawai yang telah diberi umpan kemudian diturunkan.

5. Pelampun pada tali utama bagian tengah diturunkan.

6. Setelah pancing rawai diturunkan semua kemudian pemberat ke-2 yang terhubung dengan pangkal tali utama dan pelampung diturunkan dan disesuaikan dengan kedalaman.
7. Agar pancing tidak terbawa arus, kemudian tali tersebut diikatkan ke perahu. Pancing disetting pada sore hari, dengan alasan bahwa ikan karang mencari makan pada sore hari sampai dengan menjelang pagi.

8. Penurunan (setting) pancing ini memakan waktu 1 jam.

9. Setengah jam setelah setting kemudian pancing akan ditarik kembali. Penarikkan menghabiskan waktu selama 2 jam. Pancing rawai ini dioperasikan 3 kali dalam 1 malam.

10. Ikan hasil tangkapan kemudian disimpan dalam keranjang ikan.

\section{d. Daerah Penangkapan (Fishing Ground)}

Daerah penangkapan pada umumnya di sekitar perairan Kabupaten Barru sampai dengan sejauh 80 $\mathrm{Km}$ ke arah barat. Waktu tempuh yang dibutuhkan untuk mencapai daerah penangkapan tersebut sekitar 2 sampai dengan 4 jam. Daerah penangkapan yang terjauh ke sekitar perairan Pulau Jangan-jangan. Daerah penangkapan di sekitar perairan berkarang atau berlumpur dengan kedalaman antara 30 sampai dengan $80 \mathrm{~m}$. Pada tipe dasar perairan berlumpur, ikan yang dominan tertangkap adalah jenis-jenis ikan kakap (Lutjanidae) dan pada tipe perairan berkarang didominasi oleh jenis-jenis ikan kerapu (Serranidae).

Pada Tabel 1 dapat dilihat beberapa daerah penangkapan nelayan rawai dasar di Kabupaten Barru berdasarkan pada posisi geografis.

Operasi penangkapan 1 hari (one day fishing). Nelayan pancing Kabupaten Barru memulai aktivitas mulai pukul 15.00 WITA, berangkat dari dermaga tambat Sumpang Binangae (04²4'27.1"LS, $\left.119^{\circ} 36^{\prime} 06.7^{\prime \prime B T}\right)$.

\section{e. Hasil Tangkapan}

Hasil tangkapan pancing rawai dasar didominasi oleh jenis-jenis ikan kakap dan kerapu yang juga merupakan jenis ikan target penangkapan dari alat tangkap pancing rawai dasar. Sebagai contoh berikut ini adalah hasil tangkapan nelayan pancing rawai dasar selama bulan April 2005, jenis-jenis ikan yang dominan tertangkap adalah jenis ikan kakap atau bambangan (Lutjanus malabaricus, L. johnii, L. Bohar, dan L. melanostigma), kerapu (C. boenak, E. fuscoguttatus, $C$. altivelis) dan ikan lencam. Sedangkan jenis-jenis ikan lain yang tertangkap adalah jenis ikan tenggiri, alu-alu, kurisi, bobara, pari, dan lain-lain seperti yang disajikan pada Gambar 2. 
Tabel 1. Posisi geografis beberapa daerah penangkapan ikan di perairan Barru

\begin{tabular}{|c|c|c|c|c|c|c|}
\hline \multirow{2}{*}{ No. } & \multicolumn{2}{|c|}{ Posisi Geografis } & \multirow{2}{*}{$\begin{array}{c}\text { Jenis Perairan/ } \\
\text { Kedalaman }\end{array}$} & \multirow{2}{*}{$\begin{array}{c}\text { Nama } \\
\text { Perairan }\end{array}$} & \multirow{2}{*}{$\begin{array}{c}\text { Ikan } \\
\text { Target }\end{array}$} & \multirow{2}{*}{ Keterangan } \\
\hline & Lintang (LS) & Bujur (BT) & & & & \\
\hline 1 & $4^{\circ} 22^{\prime} 37.5^{\prime \prime}$ & $119^{\circ} 32^{\prime} 35.4^{\prime \prime}$ & berlumpur / $45 \mathrm{~m}$ & Matabare & kakap & \\
\hline 2 & $4^{\circ} 20^{\prime} 50.6^{\prime \prime}$ & $119^{\circ} 30^{\prime} 52.2^{\prime \prime}$ & karang / 75m & Bajang Enge & $\begin{array}{l}\text { kerapu, kakap, } \\
\text { lencam }\end{array}$ & \\
\hline 3 & $4^{\circ} 22^{\prime} 30.6^{\prime \prime}$ & $119^{\circ} 29^{\prime} 15.4^{\prime \prime}$ & berlumpur / 60m & Tara Enge & kakap, bobara & $\begin{array}{l}\text { daerah } \\
\text { bagan }\end{array}$ \\
\hline 4 & $4^{\circ} 25^{\prime} 30.4^{\prime \prime}$ & $119^{\circ} 28^{\prime} 32.8^{\prime \prime}$ & berlumpur / $55 \mathrm{~m}$ & Awela & kakap & $\begin{array}{l}\text { daerah } \\
\text { bagan }\end{array}$ \\
\hline 5 & $4^{\circ} 266^{\prime} 43.1^{\prime \prime}$ & $119^{\circ} 27^{\prime} 47.0^{\prime \prime}$ & berlumpur / 55m & Masa Pewe & kakap & \\
\hline 6 & $4^{\circ} 27^{\prime} 56.0^{\prime \prime}$ & $119^{\circ} 27^{\prime} 43.0^{\prime \prime}$ & berlumpur / 45m & Pangkai & kakap & \\
\hline 7 & $4^{\circ} 27^{\prime} 12.9^{\prime \prime}$ & $119^{\circ} 28^{\prime} 56.0^{\prime \prime}$ & berlumpur / $45 \mathrm{~m}$ & Labutung & kakap & \\
\hline 8 & $4^{\circ} 26^{\prime} 01.0^{\prime \prime}$ & $119^{\circ} 30^{\prime} 58.9^{\prime \prime}$ & berlumpur / 35m & Toloka & kakap & \\
\hline 9 & $4^{\circ} 24^{\prime} 58.0^{\prime \prime}$ & $119^{\circ} 02^{\prime 29.3 \prime \prime}$ & berlumpur / 30m & Batuluange & kakap & \\
\hline 10 & $4^{\circ} 24^{\prime} 43.0^{\prime \prime}$ & $119^{\circ} 33^{\prime} 25.0^{\prime \prime}$ & berlumpur / $20 \mathrm{~m}$ & Anginbawe & kakap & \\
\hline
\end{tabular}

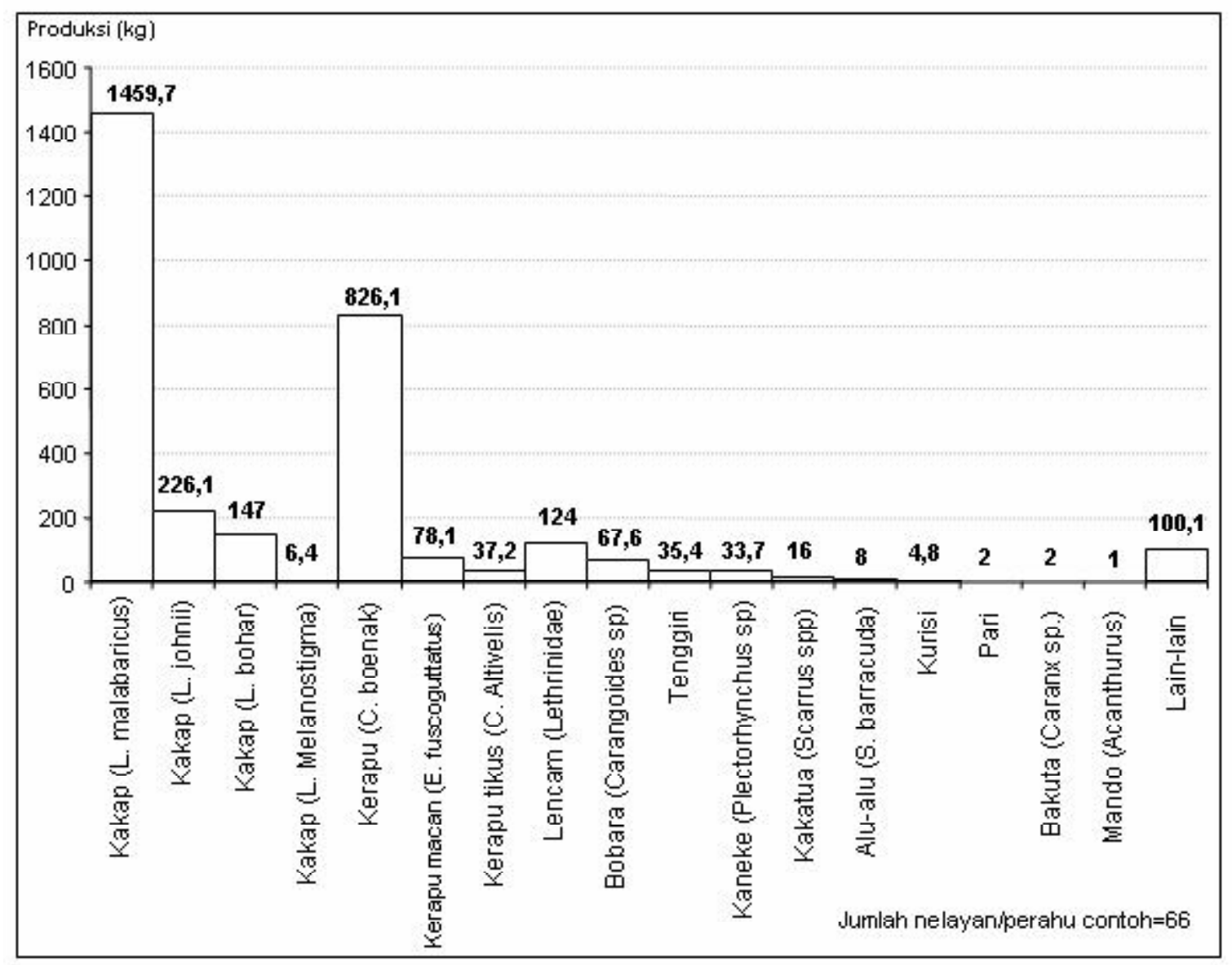

Gambar 2. Produksi (kg) ikan hasil tangkapan nelayan pancing rawai dasar selama bulan April 2005 di Desa Sumpang Binangae Kabupaten Barru, Sulawesi Selatan. 


\section{KESIMPULAN}

1. Pancing rawai dasar adalah alat tangkap untuk menangkap ikan yang hidup di dasar perairan.

2. Hasil tangkapan utama alat tangkap pancing rawai dasar di Kabupaten Barru, Sulawesi adalah jenisjenis ikan kakap (Lutjanidae) dan jenis ikan kerapu (Serranidae).

3. Tipe dasar perairan berlumpur merupakan daerah penangkapan yang hasil tangkapan didominasi oleh jenis-jenis ikan kakap, sedangkan tipe dasar perairan berkarang didominasi oleh jenis-jenis ikan kerapu.

\section{DAFTAR PUSTAKA}

Subani, W. \& H. R. Barus. 1989. Alat penangkapan ikan dan udang laut di Indonesia (fishing gears for marine fish and shrimp in Indonesia). Jurnal Penelitian Perikanan Laut (Edisi Khusus). No.50 tahun 1988/1989. 248 hal.

Widodo, J. \& E. Rahmat. Interim report. Sumber daya perikanan laut di Samarinda dan Tarakan, Kalimantan Timur. 17-23 Juni 2003. Pusat Riset Perikanan Tangkap. (Unpublish). 